\title{
ALLOY 718 FORGING DEVELOPMENT FOR LARGE LAND-BASED GAS TURBINES
}

\author{
J.F. Uginet ${ }^{1} \&$ J.J. Jackson ${ }^{2}$ \\ ${ }^{1}$ Aubert \& Duval, 75 Bld de la liberation, 09100 PAMIERS, France \\ ${ }^{2}$ GE Energy, 300 Garlington Rd., Greenville, SC 29615, USA \\ Keywords: Forging, Modeling, Turbine Rotors, Alloy 718
}

\begin{abstract}
Alloy 718 forgings have been used extensively in gas turbines for aircraft engines for decades. However their application to land-based power generation gas turbines has been limited to the size of the forgings which can be produced by available forging equipment. GE's recently developed heavy duty gas turbines now require forgings which must be produced from $915 \mathrm{~mm}$ diameter ingots which exceed $15,000 \mathrm{~kg}$. The initial hurdle was to melt these large ingots successfully without segregation defects. This was achieved and the results were discussed in a previous conference. This paper describes the unique challenges to converting these ingots into the largest Alloy 718 forgings ever produced. The development work associated with processing these ingots into a uniform fine grain microstructure with the required mechanical properties will be described. The importance of process modeling for developing a process to achieve the structure and property goals will also be discussed.
\end{abstract}

\section{Introduction}

Growth of the world's energy needs and the ageing of the installed base power generation equipment over the past decade have led to the need for larger and more efficient electrical power generating turbines to meet consumer demand. These increased power output and efficiency requirements have in turn led to higher turbine temperatures, tip speeds and more massive rotor bores to carry greater loads. GE has designed and delivered $\mathrm{H}$ and $\mathrm{FB}$ class turbines (Figure 1) which utilize Alloy 718 rotor forgings which are $>3400 \mathrm{~mm}$ in diameter and weigh over $9000 \mathrm{~kg}$ (Figure 2). Producing forgings of these sizes first demanded advances in melting large diameter $(>900 \mathrm{~mm})$ alloy 718 ingots which are free of segregation and other characteristics detrimental to subsequent billetizing and forging. Collaborative efforts between GE and melt sources have achieved this objective. ${ }^{(1)}$ Once an acceptable ingot process was established, the development of a forge practice capable of producing rotor wheels with a fine, uniform grain size to meet design needs was the next challenge. Through the extensive use of process modeling, design of experiments efforts and other laboratory studies and analyses, a thermomechanical hot working process was developed by Aubert \& Duval which meet GE Energy design and operational requirements. 




Figure 1. Half-shell view of GE Energy's 9FB gas turbine with Alloy 718 rotors.

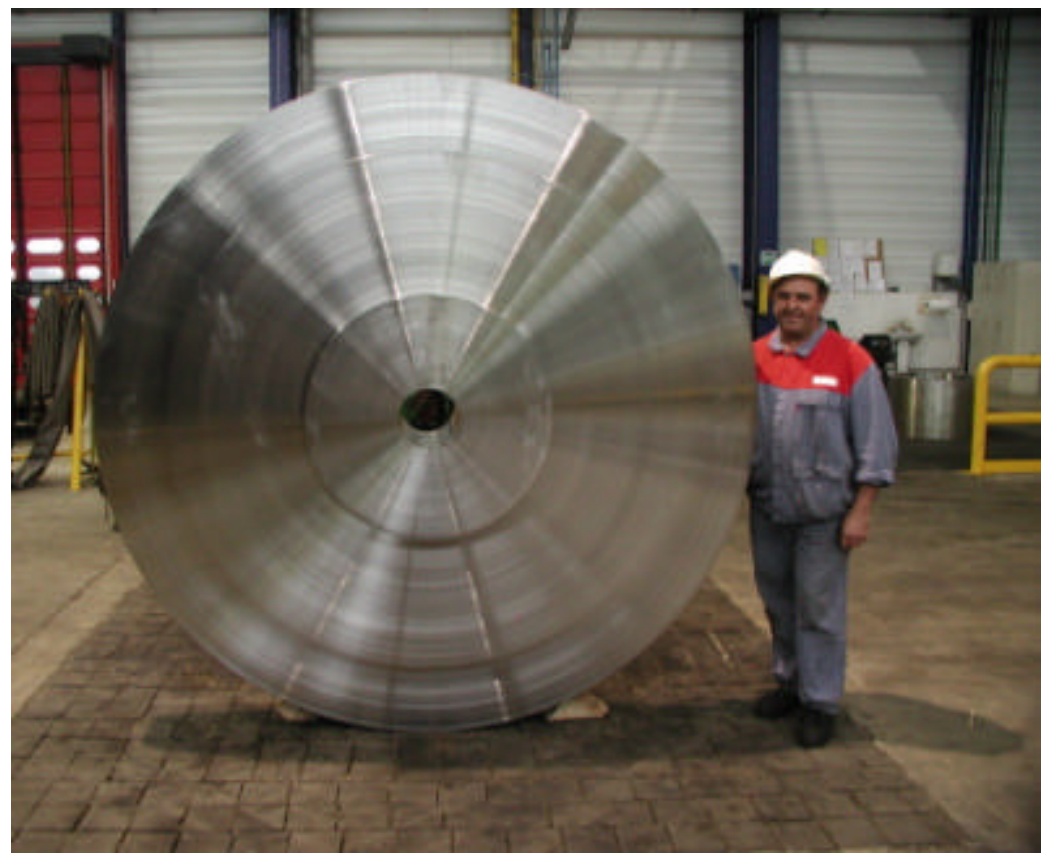

Figure 2. Alloy 718 turbine rotor forging machined for sonic inspection.

\section{Billet Processing}

Even if the remelting has kept the local solidification time to low values and thus the dendrite arm spacing and grain size as small as possible, billetizing must start from as-cast grains of several $\mathrm{mm}$ and work it throughout the ingot to finish with grain sizes of less than $100 \mu \mathrm{m}$. Based upon the final dimensions of the turbine disks and spacers to be produced, billet diameters are generally about the same size as the initial ingot diameter in order to enable the required upsetting ratios during the close die forging operations. 
Converting ingot to these billet dimensions, even using the largest available hydraulic presses is impossible in one process sequence of "upset and draw." Therefore, several heating and forging sequences with intermediate reheatings are necessary to produce these billets. Traditionally, billetizing starts at a high temperature to break up and recrystallize the as-cast structure followed by further refinement at a lower temperature in order to keep the grain size as small as possible. Generally with Alloy 718, this final forging temperature is still above the delta solvus temperature (approximately $1000^{\circ} \mathrm{C}$ ) to avoid precipitation of excessive delta platelets on the surface of the billet during the end of the billetizing operation.

A significant amount of work has been reported in the literature on the recrystallization of Alloy 718. Extensive EBSD analysis made by J.P. Thomas ${ }^{(2)}$ has shown that the recrystallizaton mechanism in Alloy 718 is not really a classical one of discontinuous recrystallization, but is more complex, combining the disorientation of cells inside the initial grains, including twins, and nucleation of highly disoriented cells at the grain boundaries or twins. Local Deformation, Deformation Rate and Temperature are primary influencing parameters governing this recrystallization phenomena. However, as there is a competition between the nucleation and the recovery processes, it is not obvious that temperature is always a positive parameter in the total thermomechanical working window when attempting to produce uniform fine grain forgings. Laboratory testing at Aubert \& Duval on small pancakes produced directly from ingot illustrate this point. Figure $3 \mathrm{a}$ shows the as-cast structure after an initial preheating at $\mathrm{T}^{\circ} \mathrm{C}$ and a deformation at $0.5 \mathrm{X}$. Figure $3 \mathrm{~b}$ shows the same microstructure after a re-heating at $\mathrm{T}-50^{\circ} \mathrm{C}$ for 2 hours. Figure $4 \mathrm{a}$ shows the as-cast structure after an initial preheating at $\mathrm{T}-80^{\circ} \mathrm{C}$ and a deformation of $0.5 \mathrm{X}$. Figure $4 \mathrm{~b}$ shows the same microstructure after re-heating to $\mathrm{T}-50^{\circ} \mathrm{C}$ for 2 hours.

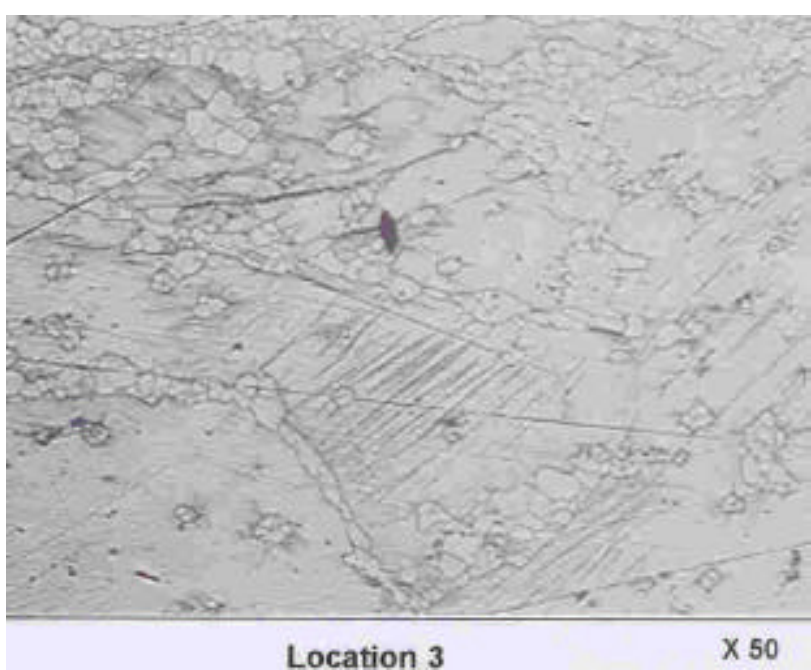

(a)



(b)

Figure 3. Laboratory test samples of Alloy 718 with $0.5 \mathrm{X}$ deformation at $\mathrm{T}^{\circ} \mathrm{C}$ (a) as-deformed and (b) after reheating at $\mathrm{T}-50^{\circ} \mathrm{C}$ for 2 hours. 


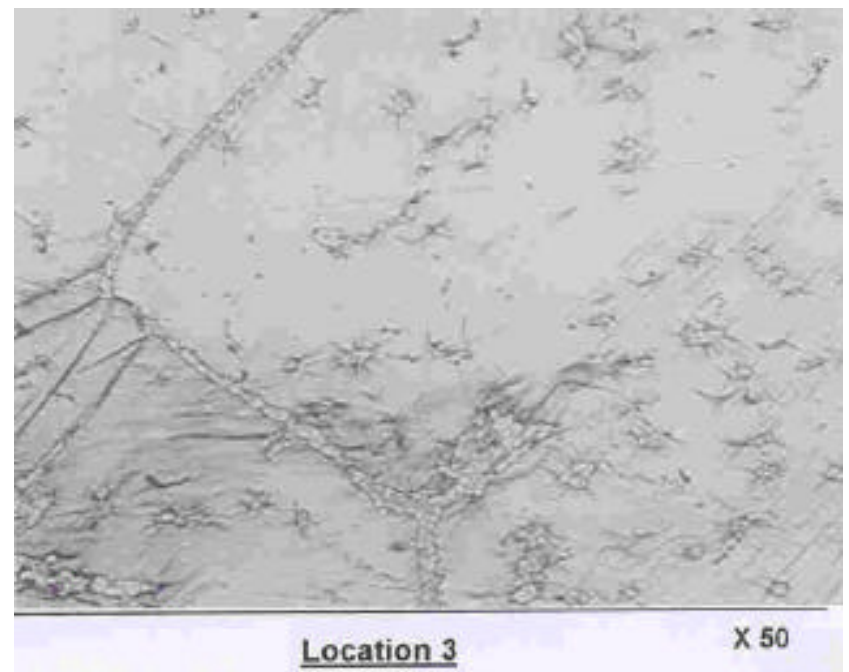

(a)



(b)

Figure 4. Laboratory test samples of Alloy 718 with $0.5 \mathrm{X}$ deformation at $\mathrm{T}-80^{\circ} \mathrm{C}$ (a) asdeformed and (b) after reheating at $\mathrm{T}-50^{\circ} \mathrm{C}$ for 2 hours.

These figures show that after static recrystallization for 2 hours at $\mathrm{T}-50^{\circ} \mathrm{C}$, the same local deformation is more efficient when performed at the lower deformation temperature of $\mathrm{T}-80^{\circ} \mathrm{C}$ compared to deformation at $\mathrm{T}^{\circ} \mathrm{C}$. This is in fact very typical of structure with a low fraction of dynamic recrystallization. Since it is very difficult in normal upset and draw operations to obtain high deformation levels which would guarantee complete dynamic recrystallization, it would be more beneficial to combine a sequence of lower temperature drawing followed by higher temperature upsetting to improve grain size uniformity. This approach also has the advantage of potentially enabling higher upset ratios possible at the higher temperatures.

Alloy 718 is subject to classical grain growth when heated to super delta solvus temperatures. Since it is very difficult to upset and draw this alloy at lower temperatures during the billetizing process, processing is usually performed at temperatures just slightly above this delta solvus to minimize grain growth near the end of billetizing. However, S. Coste ${ }^{(3)}$ has shown that time has a great influence on this grain size. Figure 5 shows that starting from a grain size of $30 \mu \mathrm{m}$ (ASTM 7) grain size will grow up to $100 \mu \mathrm{m}$ (ASTM 4) after only 30 minutes at $1040^{\circ} \mathrm{C}$ with a $5 \% \mathrm{Nb}$ Alloy 718 chemistry typical for large ingots.

However, it is extremely difficult to control billet temperatures throughout to such a narrow temperature range (eg. just above the delta solvus) when you have to heat very large billets to process temperatures or cool down to room temperature. Results of process modeling shown in Figure 6 indicate that it will take 6 hours of furnace time to get temperature uniformity better than $5^{\circ} \mathrm{C}$ in a $900 \mathrm{~mm}$ diameter billet after 15 minutes processing out of the furnace (neglecting adiabatic heating of the core). On the same billet, as shown in Figure 7, it will take almost 1 hour to decrease the first $20^{\circ} \mathrm{C}$ during the air cooling after the final drawing operation. Even with a water cooling, these first $20^{\circ} \mathrm{C}$ in the super solvus domain are hardly lost within 30 minutes which is sufficient time to get significant grain growth. This illustrates the difficulty of working such large billets in a consistent manner with the classical cogging on a forging press when a fine grain practice, finer than ASTM 4 is the objective.

In spite of the cited difficulties associated with the billetizing process, careful control of shop processing parameters can be maintained to the meet the desired metallurgical objectives. Since reheat times and temperatures are extremely critical, those shop procedures must take into 
account the number of parts in the preheat furnace (which can be restrictive), the cascading of part and furnace temperatures, the length of the forging cycle and the control of reheat times in order to keep the core and surface temperatures in the proper range. These many processing constraints demand that tight control of handling and forge cycle times be maintained which can unfortunately lead to reduced press productivity. After more than 6 years of practice, a billetizing process for $900 \mathrm{~mm}$ diameter Alloy 718 ingots has now been established which can guarantee the desired microstructure for subsequent forging into large gas turbine rotor parts.

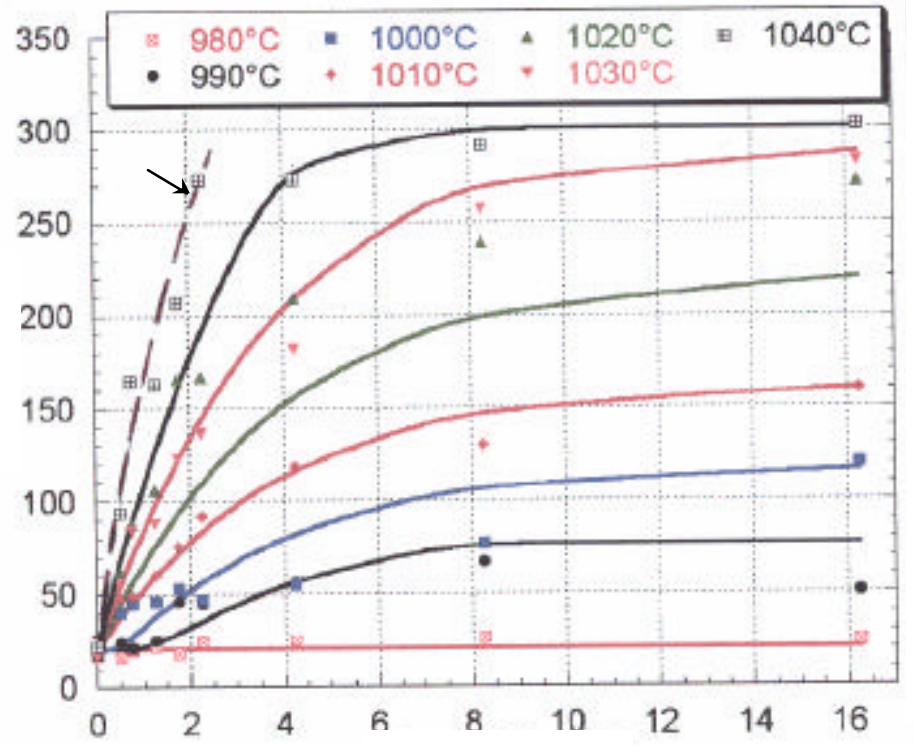

Figure 5. Example of grain growth in forged Alloy 718 at various temperatures ${ }^{(3)}$.



Figure 6. Time to reheat a $900 \mathrm{~mm}$ Alloy 718 billet throughout after 15 minutes of cogging. 


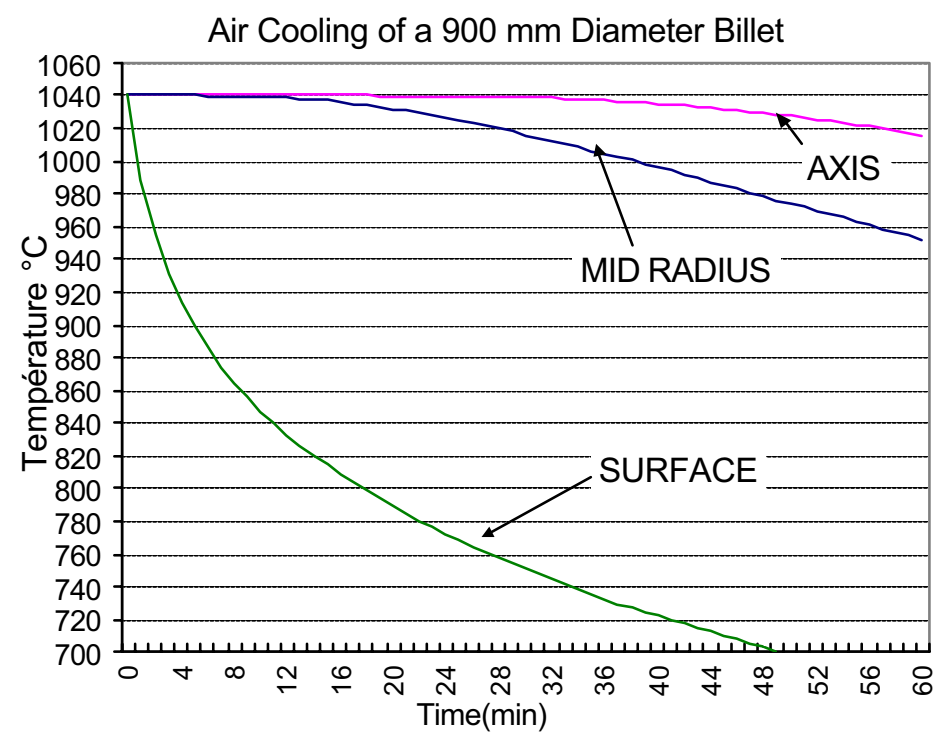

Figure 7. Time to cool a $900 \mathrm{~mm}$ Alloy 718 billet throughout after cogging.

\section{Close Die Forging}

During the close die forging process, a large, 65000T press can be used to achieve good control of the key parameters which govern the local deformation, local strain rates and to some extent, temperatures of the Alloy 718 forgings. This high press capacity affords the opportunity to decrease the temperature below those typically used for Alloy 718 and therefore work with some delta phase precipitates pinning the grain boundaries. This large press can also control deformation rate to avoid excessive adiabatic heating during the processing. However, to prevent buckling of the very large $(>15000 \mathrm{~kg}) 900 \mathrm{~mm}$ diameter billet and achieve a fine, uniform grain size, it is necessary to carefully control initial preheating to avoid an excess of precipitation of acicular delta phase which is known to have a detrimental effect on the recrystallization fraction. With the press capabilities known and previously acquired knowledge of Alloy 718 deformation behavior, process modeling was used to establish initial close die forging parameters.

With a $5 \%$ average content in $\mathrm{Nb}$, a preheat temperature of $980^{\circ} \mathrm{C}$ is considered safe to prevent any grain growth (see Figure 5) and preheat temperatures up to $1000^{\circ} \mathrm{C}$ are still likely to be acceptable. However, deformation in this temperature range can lead to banding, particularly along the axis of the billet. This banded microstructure can be even more pronounced after deformation and further reheating between forging steps. Figure 8 shows banding which occurred along the axis of the billet/forging after a local deformation of $1.5 \mathrm{X}$ in 2 steps. The adiabatic heating during forging (which can be as high as $1036^{\circ} \mathrm{C}$ in the core) combined with the reheating at $1000^{\circ} \mathrm{C}$ can induce grain growth in lower $\mathrm{Nb}$ areas of the dendrites.

At the same time, due to slow handling of these large forgings and die chill effects, it is very difficult to avoid a decrease of temperature and a dead zone effect near the forging surface with an excess of acicular delta phase and a total lack of recrys tallization as shown in Figure 9. 


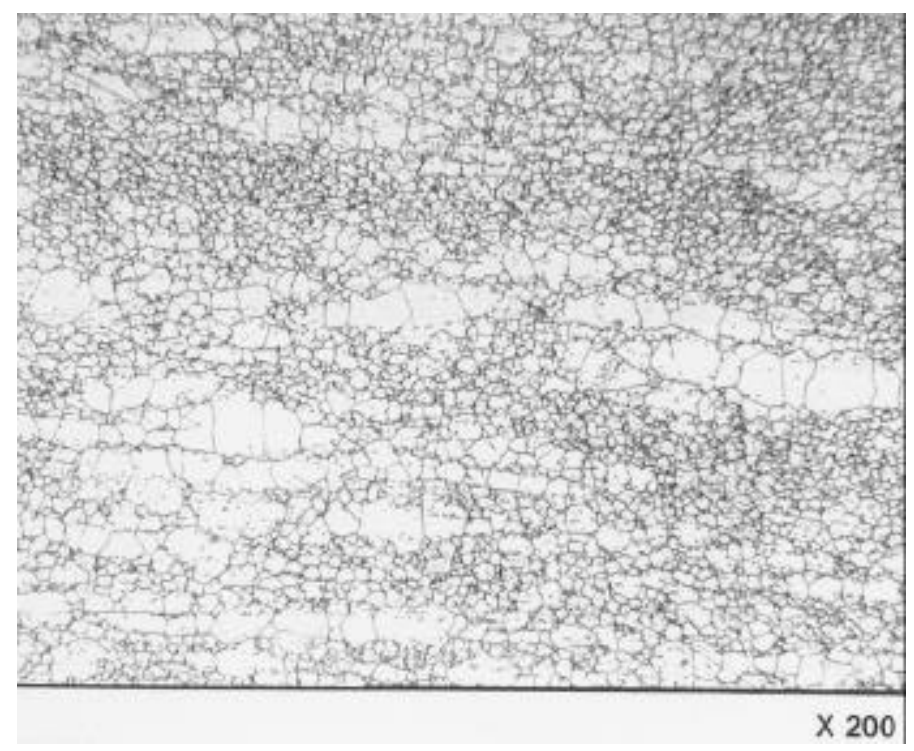

Figure 8. Banded structure along the forging axis of Alloy 718 locally deformed $1.5 \mathrm{X}$ in 2 steps at $1000^{\circ} \mathrm{C}$.



$\times 100$

Figure 9. Unrecrystallized microstructure near the surface of the forging shown in Figure 8.

To address these issues, further modeling of the close die forging process was performed. After several iterations of modeling it became apparent that a shielding technique of some type could prevent heat loss and improve local deformation at the billet end surfaces while minimizing the adiabatic effect along the axis of the forging. Figures $10 \mathrm{a}$ and $10 \mathrm{~b}$ compare the deformation map with and without shielding of the surface. Figures $11 \mathrm{a}$ and $11 \mathrm{~b}$ compare the temperature map with and without shielding the surface during an upsetting step of the process. These models clearly show the great advantage of this technique upon the homogeneity of the deformation and, hence local temperature. Note that with shielding, the adiabatic heating is reduced in the core by $15^{\circ} \mathrm{C}$, which $\dot{\mathrm{s}}$ significant in this highly sensitive domain of temperature with respect to grain growth. Also note the increase of metal flow and deformation near the billet surface and decreased deformation in the core predicted with shielding, both improving deformation uniformity. 


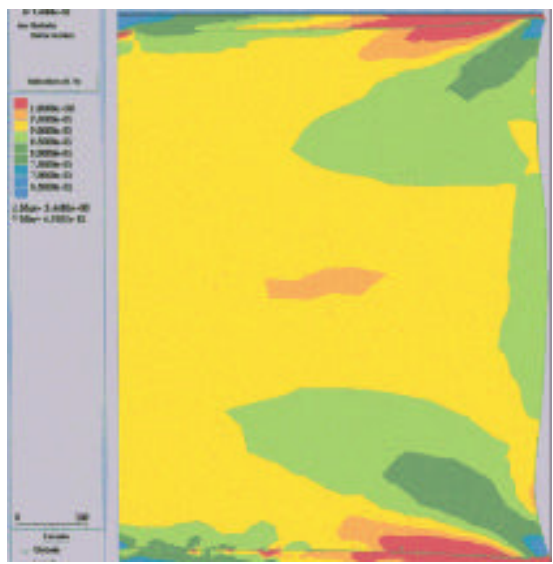

(a)

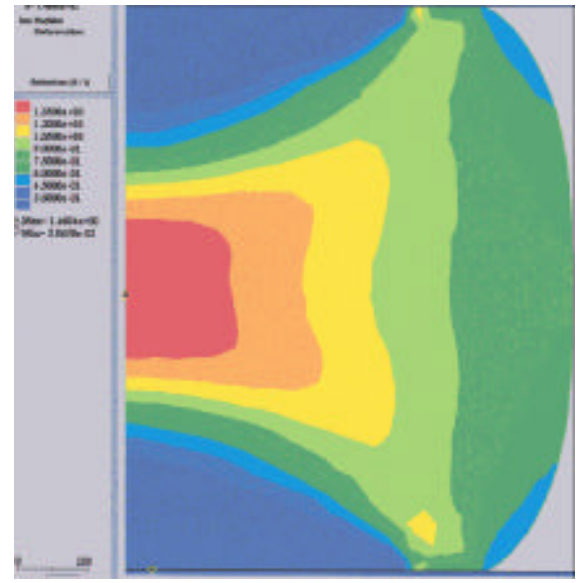

(b)

Figure 10. Deformation map after upsetting of Alloy 718 billet (a) with shielding and (b) without shielding.

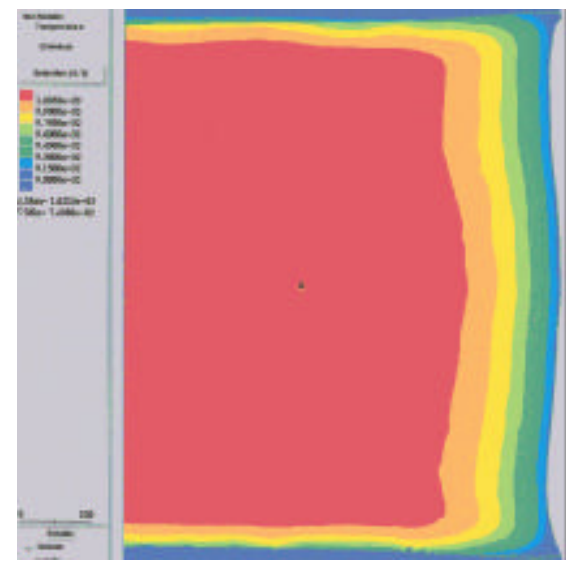

(a)

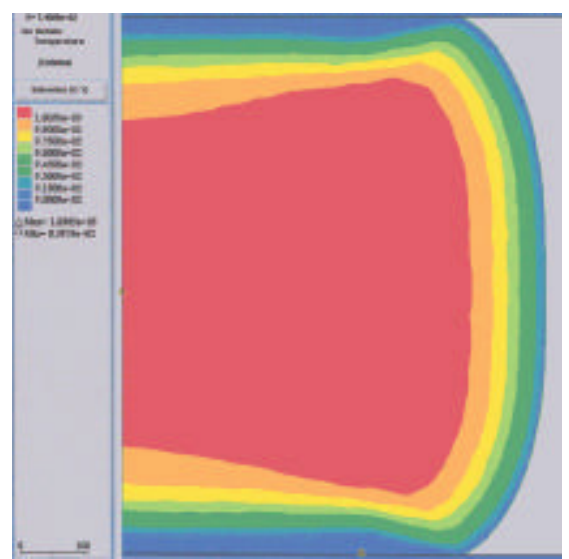

(b)

Figure 11. Temperature map after upsetting of Alloy 718 billet (a) with shielding and (b) without shielding.

Close die forgings made utilizing a shielding technique were processed to demonstrate its potential benefit. Figure 12a shows the microstructure near the bore surface of a forging made with shielding. Although there is still a duplex microstructure, it has been greatly improved by this technique (compare to Figure 9). Grain size in this location is $80 \% 10$ ALA9 + 20\% 6ALA4, and can been accepted with respect to specification mechanical properties. Figure $12 \mathrm{~b}$ shows the microstructure at the bore mid-thickness of the same part to have a homogeneous and uniform grain size of ASTM 9ALA8. These results clearly illustrate the significant benefit of the shielding technique. 


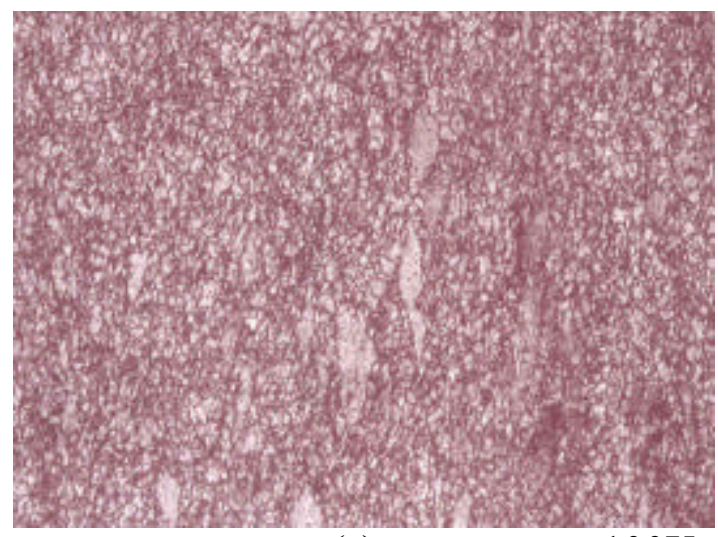

(a)

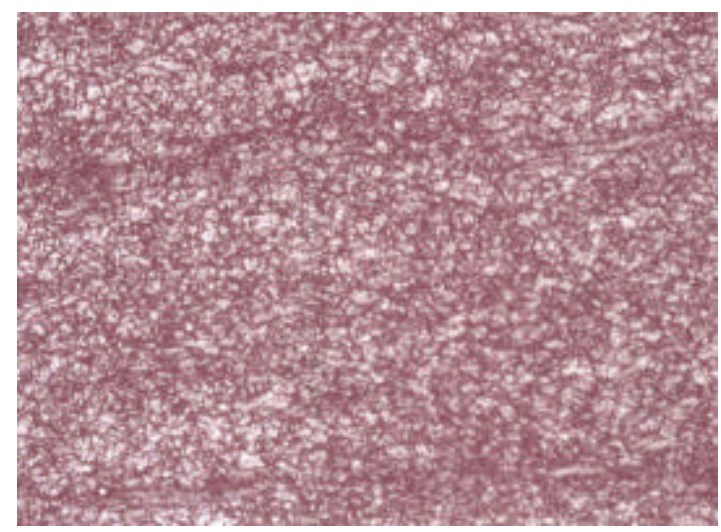

(b)

$100 X$

Figure 12. Microstructure of an Alloy 718 wheel forging made using a shielding technique observed (a) near the bore surface and (b) along the bore mid-thickness.

In the last step of the close die forging process, the final shape is given to the part and this operation corresponds to the maximum required press force. It is desirable to make this press stroke as short as possible. However, since some areas of the part may be susceptible to an abnormal grain growth (AGG) described by J.F. Uginet ${ }^{(4)}$, there is a minimum required strain which must be achieved in certain design critical locations of the part. To address these concerns and assure that there is no AGG in those critical part locations, extensive process modeling was used to define die shapes and the final deformation step.

\section{$\underline{\text { Influence of Solutioning and Aging, Times and Temperatures. }}$}

In order to optimize the heat treatment of the final forgings, studies were conducted using asforged sections from various locations (rim, bore, etc) to determine the solution and aging times and temperatures which would result in acceptable properties and grain size throughout. This approach was preferred to a more general HT study in order to take into account the real state of delta precipitation and residual cold work of the structure in the forgings. Upon completion of these studies, times were adjusted based upon part dimensions to obtain a solution heat treatment soaking time of 2 hours at temperature in the core of the part followed by subsequent aging for times also suitable for the core. Using these heat treat conditions, several large turbine forgings were processed, heat treated and then tested over a range of temperatures. Figure 13 shows the tensile properties of these forgings as a function of test temperature. This data represents est specimens taken from various locations in the forging (ie. bore, web area and rim) and illustrates that tensile properties are reasonably uniform regardless of location which is consistent with the relatively uniform grain size and microstructure observed in the forgings. 


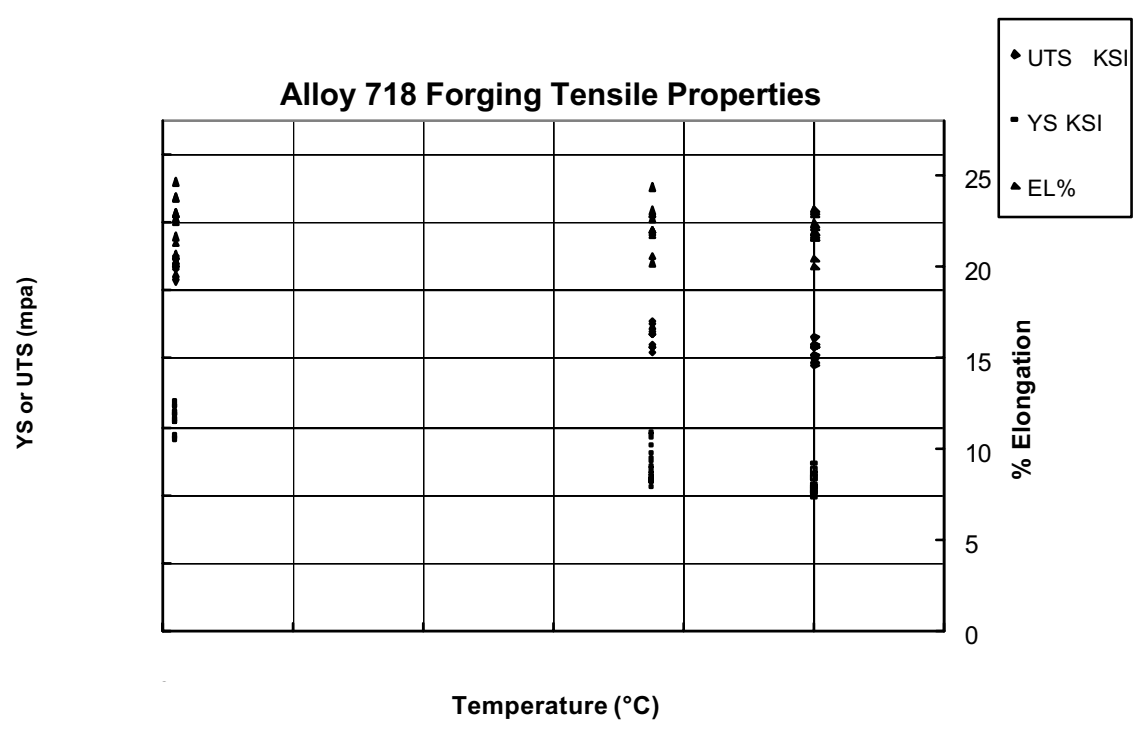

Figure 13. Typical tensile properties of an Alloy 718 forging made from a $900 \mathrm{~mm}$ diameter ingot using shielding and well controlled processing.

\section{$\underline{\text { Strain Flow and Carbide Distribution }}$}

Due to the large diameter of the finished forging compared to the initial ingot diameter, there is a high upsetting ratio which results in the stretching of the material in the radial direction. During that radial stretching interdendritic areas of the last solidified material are heavily worked in this direction. This effect is beneficial for the grain size, however, carbides or nitro-carbides generally precipitated in these areas are spread along the flow lines in this radial direction. When testing the material perpendicular to that direction (axial with respect to the forging) a lack of ductility compared to the other directions is often observed. Figure 14 illustrates such stringers which may be found particularly in the top axis of the ingot.

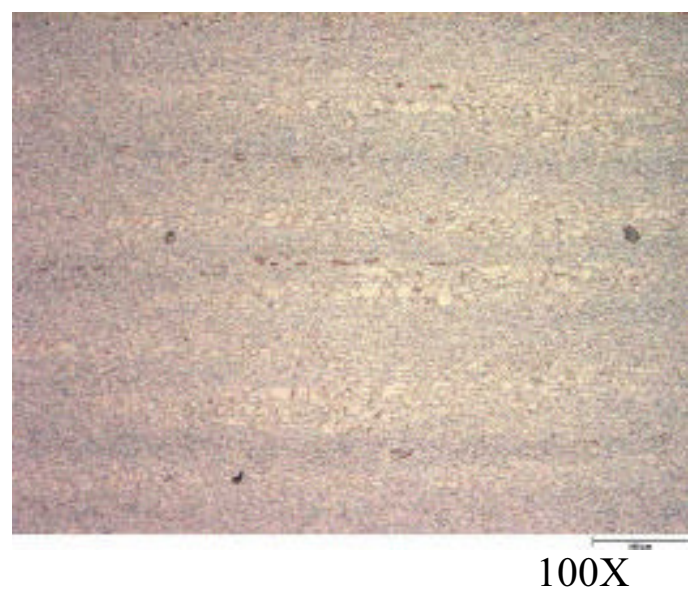

Figure 14.Example of carbide and nitro-carbide stringers observed along the axis of an Alloy 718 forging made from a $900 \mathrm{~mm}$ diameter ingot. 
This carbide stringer effect can be found in the bore area of the part where axial elongation may fall down to about $10 \%$, which is still acceptable as regard to the local stresses which are mainly radial in this area. However, the occurrence of stringers needs to be reduced if possible, perhaps by combining a reduction of the dimension of the stringer during the solidification and a more effective break-up and dispersion during the billetizing and forging operations.

\section{Conclusions and Recommendations}

As illustrated in this paper, control of microstructure in large turbine rotor components can be mastered by understanding and dealing with the precise recrystallization behavior of this $5 \% \mathrm{Nb}$ grade of Alloy 718. To do so requires a long and sometimes complicated process to produce the fine, uniform grain sized microstructure required to achieve desired mechanical properties. Each step of this long process is critical and must be well controlled and reproducible. Of particular importance is the billetizing process which should result in a fully controlled grain size finer than ASTM 4, necessary for the final close die forging step. Special shielding techniques can be very beneficial during the finish forging operations to improve uniformity of deformation and microstructure and to avoid surface effects which could lead to a waste of precious material.

These thermomechanical processing challenges however, can not ignore the effects which may result from the initial melting and solidification of the ingot. It has been shown that local areas of segregation can strongly influence grain size variations and that small quantities of carbides spread during the forging process can impact the tensile ductility. In spite of the large diameter and weight of the initial ingots, these occurrences of segregation need to be addressed by a common effort between melting and forging processes. The further development of the modeling of microstructure during close die forging would also be very beneficial to achieving desired structures and properties. Modeling efforts in this area are currently in progress and codes are now being validated on large components after initially determining equations using laboratory experimentation. It is expected that when validated, such modeling tools will greatly enhance the opportunity to create more imaginative processes, avoid hazardous trials on expensive parts and open up new areas for the processing of large superalloy forgings.

\section{References}

1. R.C. Schwant, et al, "Large 718 Forgings for Land Based Turbines," $4^{\text {th }}$ Symposium on Superalloy 718, 625 and Various Derivatives, Edited by E.A. Loria, TMS, 1997, 141-162.

2. J.P. Thomas, F. Montheillet, C. Dumont, "Microstructural Evolutions of Superalloy 718 during Dynamic and Metadynamic Recrystallizations," Proc. Thermec 2003 Material Science Forum, Vol 426-432, 2003, 791-796.

3. S. Coste, Thèse "Determination des Lois D'évolution Microstructurale de L'alliage 718 Lors du Matriçage," ENSIACET, 118 rte de Narbonne, 31097 Toulouse France, 2003.

4. J.F. Uginet, B. Pierraggi, "Study of Secondary Grain Growth on 718 Alloy," $4^{\text {th }}$ Symposium on Superalloy 718, 625 and Various Derivatives, Edited by E.A. Loria, TMS, 1997, 343-352. 